\section{A multidisciplinary approach to scaling up HIV/AIDS treatment and care: the experience of the Bahamas}

\author{
James Fitzgerald, ${ }^{1}$ \\ Mercelene Dahl-Regis, ${ }^{2}$ \\ Perry Gomez, 2 \\ and Amalia Del Riego ${ }^{1}$
}

The Bahamas has a total population of 314000 (1). It is estimated that there are now 5600 to 8700 adults and children living with HIV/AIDS in the country (2). Approximately 2500 women in the age range of 15 to 49 years are infected with HIV. The Ministry of Health $(\mathrm{MOH})$ of the Bahamas and the surveillance system of the nearby Turks and Caicos Islands report that approximately $25 \%$ of all HIV infections among persons in those two jurisdictions are found in the Haitian immigrant population. Various estimates suggest that the Haitian population in the Bahamas represents $25 \%$ of the country's total population (3). Historically, the majority of Haitians found in the Bahamas have fled Haiti for economic reasons.

To address the HIV/AIDS epidemic, the Bahamas has developed effective HIV/AIDS prevention, care, and treatment policies that have been applied since $1985 .^{3}$ The Bahamas National AIDS Program has developed strategies and interventions in the areas of prevention and education, comprehensive care (clinical and social interventions), support services, and surveillance and research (clinical and behavioral) (4).

The National AIDS Program coordinates the national response, and services are provided throughout the public health care system as well as in the private sector. Strong private and public partnerships have been built, as evidenced by the intersectoral HIV/AIDS Resource Committee, which is composed of government agencies and nongovernmental organizations (NGOs). The Committee plays an important role in coordinating the response to HIV/AIDS across sectors, and it provides support as required to the National AIDS Program of the Bahamas. The Samaritan Ministry, a religious organization dedicated to providing social care and support to persons living with HIV / AIDS, is an active member of the Committee, as is the AIDS Foundation of the Bahamas.

The Bahamas has been providing comprehensive care for HIV-positive individuals and perinatally exposed infants in two specialized clinics since 1985. Services, including antiretrovirals (ARVs) and other drugs for those unable to pay, are provided free of charge. The services can be broadly classified into clinical care and clinical support services. The support services at the clinic include laboratory, ra-

\footnotetext{
3 Ingraham HA. Remarks at the United Nations General Assembly Special Session on HIV/AIDS, New York, 25 June 2001.
} 
diology, pharmacy, and counseling; through home visits there is patient and family education, nutrition support, surveillance, and contact tracing.

The Bahamas program for the prevention of HIV transmission from mother to child was initiated in 1995. That program has seen a significant reduction in the rate of HIV transmission from HIVinfected mothers to their newborn children, from $28 \%$ in 1995 to $3 \%$ in 2002. From 1993 to 2002 there was a $38 \%$ decline in HIV prevalence among pregnant women. Using public funding, in 1998 the Bahamas MOH initiated limited ARV therapy for children. The range of policies applied by the Bahamas contributed to an $89 \%$ reduction in AIDSrelated deaths among children between 1994 and 2002, and an overall 56\% reduction in AIDS-related deaths in both adults and children during the same period.

In a December 2000 report on the price of HIV/AIDS medicines, the Doctors without Borders group reported that the yearly ARV treatment cost in the United States ranged from US\$ 10000 to US\$ 15000 per patient, while the annual gross domestic product per capita in developing countries ranged from US\$ 140 to US\$ 6190 (5). Given those high ARV prices, competing demands, and limited resources that they had, developing countries struggled to make allocations for ARV therapy in their national health budgets.

In June 2002, Caribbean countries successfully completed a round of negotiations with researchbased manufacturers of branded ARVs through the World Health Organization (WHO) and the Joint United Nations Programme on HIV/AIDS (UNAIDS) Accelerated Access Initiative (AAI) (6, 7). The negotiations were the culmination of a lengthy process involving a series of consultations among countries of the Caribbean Community (CARICOM), with technical support from WHO, UNAIDS, and the Pan American Health Organization (PAHO). These negotiations resulted in the production of a reference document that reviewed the status of HIV/AIDS care and treatment in the Caribbean and that also proposed a logical framework of activities to be developed and implemented at the regional (Caribbean) level to support in-country scale-up processes throughout the Caribbean Community (8).

Following the negotiations, however, few Caribbean countries found themselves in a position to readily take advantage of the negotiated ARV prices. A number of the countries indicated that the prices through the AAI were still too high to make treatment programs affordable, and others indicated that national treatment programs were not sufficiently developed to provide ARV treatment. The countries recognized that considerable effort would have to be made to develop health infrastructure and resources in order to deliver care and treatment to people living with HIV/AIDS (PLWHA). At a meeting on 19 September 2002, CARICOM, PAHO, the United States Department of Health and Human Services, and the William Jefferson Clinton Presidential Foundation agreed to combine efforts in the Caribbean and support countries ready to expand care and treatment. The Bahamas agreed to pilot an intensive, practical, integrated scale-up process that would, in less than one year, greatly increase the numbers of PLWHA with access to ARV treatment and care.

\section{CHALLENGES IDENTIFIED IN SCALING UP}

Officials in the Bahamas knew that the scaleup process there would require a consolidated and integrated approach in the development of services and human resources and in program administration and management. At an early stage the Ministry of Health identified a number of specific challenges to be addressed if the scale-up was to be successful. Infrastructure and services required investment and development to increase the number of PLWHA receiving ARV therapy. In addition, the Bahamas has a centralized health service, with HIV/AIDS care and treatment provided at the Princess Margaret Hospital (PMH) in the city of Nassau and the Rand Memorial Hospital (RMH) in the town of Freeport. In order to expand treatment and care, the national health authorities considered that HIV care services would have to be decentralized from these reference centers to public health clinics throughout the Bahamas. At the same time, a number of services would require consolidation at the central level, especially training, education, and laboratory services.

Strengthening and expanding laboratory services at the local level was needed to support the scale-up process. Laboratory capacity existed to carry out basic HIV tests and other blood chemistry analyses at public health reference institutions, but more complex HIV diagnosis, including CD4 cell count tests, viral load tests, and Western Blot confirmatory tests, were carried out at the Infectious Disease Laboratory of the Hospital for Sick Children in the city of Toronto, Canada.

The Bahamas considered the rate-limiting step in scaling up to be the development of an appropriate pool of qualified, trained personnel who could manage and expand the delivery of services. Training would be required in clinical care and in laboratory, pharmacy, and counseling support services. In addition, the pending impact of expanding services in HIV/AIDS care and treatment on 
human resource requirements in other services was identified as a critical issue. The national health authorities expressed concern that the scale-up process would adversely affect the capacity of the health system to provide other basic health services, and at the same time impact the quality of services being provided. A further issue to be considered was how the country would in fact expand human resource capacity as the scale-up process unfolded.

The Bahamas $\mathrm{MOH}$ recognized that the collection of data on costs for services and essential public health supplies would be a major challenge in the initiative. Determining those costs was considered essential in permitting the country to effectively program the number of patients to receive ARV treatment at each stage of the scale-up process. Developing and applying a cost analysis methodology for assessing the future cost of medication, supplies, and clinical care and support services was set as a priority early in the planning process. Additional financing would be required to support the scaling-up process. The Government of the Bahamas considered that external financial support would be needed in order to fully implement the scale-up plan without compromising other essential public health interventions. Prior to the scale-up, the Government of the Bahamas had already increased the budget allocation for the National AIDS Program and services. If external financial resources were not available, full implementation of the scale-up plan would be virtually impossible.

With the proposed decentralization of HIV/ AIDS care and treatment services during scale-up, the need to provide adequate information and education to health professionals and the community was considered essential. This would minimize the possibility of stigmatization of and discrimination against PLWHA who would be seeking care and treatment in public health clinics (9).

\section{KEY INTERVENTION AREAS AND STRATEGY FOR SCALE-UP}

Faced with the challenges of scaling up, the Bahamas established a National Multidisciplinary Team (NMT) with competencies and experience in key areas. The NMT was comprised of experienced health care providers, program managers, senior managers, and decisionmakers from the Bahamas $\mathrm{MOH}$. The NMT would receive important input from other stakeholders, including Social Services, the labor and private sectors, and NGOs. In developing a project document, the team received technical collaboration and support from WHO
FIGURE 1. Key areas of intervention for scale-up of HIV/ AIDS treatment and care in the Bahamas, 2003-2005

1. Infrastructure for health systems:

- Laboratories: limited availability of specialized laboratory services

- Pharmacy: underutilized pharmacy services and excessive drug costs

- Training and research: inadequate capacity

- Decentralization: to require improved infrastructure at the secondary and primary health institution level

2. Health services:

- Crowded tertiary care institutions providing all levels of care

3. Information management:

- Inadequate systems for managing drugs and kits, reagents, transportation, educational material, laboratories, and clinical care

4. Human resource capacity-building:

- A shortage of trained health professionals for the clinical management of patients and for support services such as laboratories and pharmacies

- Inadequate social support interventions and personnel at the community level

and PAHO staff, including personnel from PAHO technical programs based in Washington, D.C., the Caribbean Epidemiology Center in Trinidad and Tobago, and the PAHO Country Office in the Bahamas. Support was also provided by experts from a number of public health institutions in the United States, including the Centers for Disease Control and Prevention. The Clinton Foundation guided the development of the project document and facilitated the identification of an important group of resource experts from institutions such as the Pangea Global AIDS Foundation, the Institute for Healthcare Improvement, and McClain and Associates.

A series of initial consultations was held by decisionmakers within the Bahamas $\mathrm{MOH}$, the Clinton Foundation, and PAHO to identify the core areas of intervention (Figure 1) on which the scaleup process would focus. The partners held their first meeting in the city of Nassau, Bahamas, in early October 2002, with a strong political mandate from the Bahamas $\mathrm{MOH}$ to move forward into the planning process. Thereafter, a number of important steps and activities were conducted at the country level by the NMT to facilitate achievement of objectives in the first year, as described below.

\section{Planning and consensus building}

The initial program of work included site visits to treatment and care centers in the Bahamas. Discussions were held with health professionals in 
the health centers in each of the key areas of intervention. The purpose of the discussions was twofold: (1) for the international partners to obtain a better understanding of the health system and services in the Bahamas and (2) for the NMT to identify principal objectives for the scale-up process. The analytical component of this phase included a review by the NMT and the international partners of health policy and HIV/AIDS plans, an evaluation of health system capacity in the delivery of services, and an assessment of available resources. In addition, the Bahamas $\mathrm{MOH}$ initiated a process of in-country consultation to inform and communicate with all stakeholders as well as to broaden consent and participation across sectors. During this process, discussions were held with the AIDS Foundation and other Bahamian NGOs, labor unions, the country's customs and immigration services, and the local pharmaceutical sector.

\section{Scale-up models and gaps analysis}

To achieve scale-up, it was necessary to define the resources and capacity of the health system as well as the services needed to provide care to an increased number of patients. Taking the primary objectives of the scale-up (that is, rapidly increasing the number of PLWHA receiving care and treatment), the NMT and the international partners defined models for the Bahamas $\mathrm{MOH}$ in the areas of clinical care and support, health organization and systems, and information management. The resources and capacity needed to make each of the models operational were estimated and measured by the NMT and the international partners against existing resources and capacity in a "gaps analysis." The key areas of the health system assessed in the gaps analysis are presented in Figure 2. In this way the NMT determined the main gaps within the health system as well as the resources and capacity needed to expand treatment and care. The results of the analysis in fact largely confirmed that the principal challenges to the scale-up process would continue to be the development and deployment of adequately trained human resources throughout the clinical care and support services as well as the mobilization of financial resources.

\section{Development of the logical framework}

The NMT and the international partners then applied a logical framework, taking the primary goals of the scale-up process and translating them into expected results, objectives, and activities. An operational plan was developed, and within it the
FIGURE 2. Key areas assessed in the Bahamas "gaps analysis," December 2002

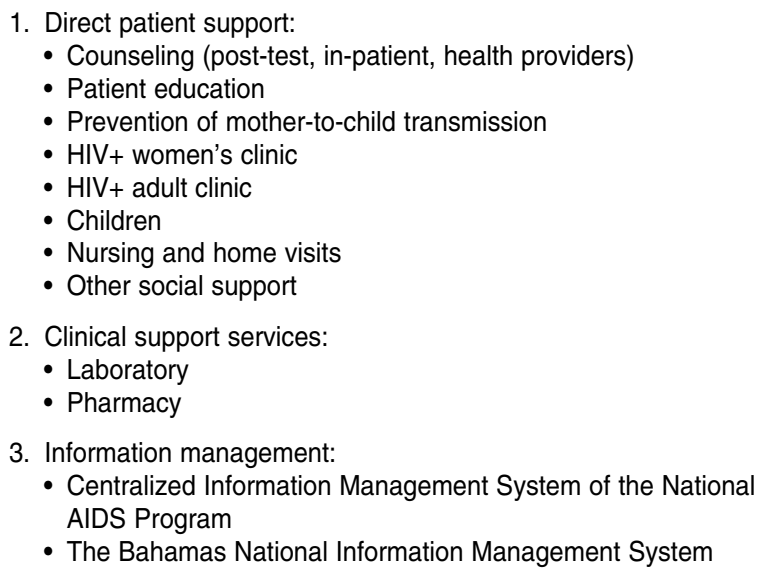

NMT identified three goals: (1) to extend comprehensive care to all PLWHA by 2005; (2) to prevent the transmission of HIV, specifically targeting partners and children of PLWHA; and (3) to establish a national HIV/AIDS resource center to coordinate national programs.

At the same time, the NMT and the international partners prepared cost estimates in accordance with the scale-up objectives. Costs were calculated based on the resources and the capacity that the gaps analysis had indicated were needed. The costs were divided into two categories: (1) one-time capital investment costs (e.g., building of new laboratories, refurbishing of the coordination center for the National AIDS Program) and (2) operating costs (Figure 3). It was estimated that US\$ 23.4 million would be required over a three-year period to ensure the provision of comprehensive care and treatment to 6900 PLWHA, including approximately 3200 receiving ARV therapy. The framework for monitoring and evaluation of program implementation was developed by the NMT and the international partners, focusing on process, impact, and outcomes.

\section{Implementation phase}

Prior to implementation the scale-up proposal was finalized by the NMT and submitted to the Clinton Foundation in order to facilitate fundraising. A commitment of US\$ 1 million for the 2003-2005 period was secured by the Clinton Foundation from the private sector in the Bahamas to support some of the initial activities, in particular 
FIGURE 3. Estimated costs for scaling up HIV/AIDS treatment and care in the Bahamas for the period of 2003-2005

1. Capital investment costs:

- Equipment and capital improvements US\$ 0.6 million

2. Operating costs:

- Medicines

HIV/AIDS antiretroviral medicines

Medicines used against opportunistic infection

- Outpatient primary and specialized

medical care

Personnel

Specialized care providers

- In-patient medical care

Personnel

Hospital operating costs

- Laboratory services

CD4 tests

Viral load monitoring

ELISA

Other tests

Shipping of samples

- Prevention and education

Personnel

Supplies

- Training and technical assistance

- Research

- Surveillance

- Monitoring and evaluation

- Program support Administration

Transportation

US\$ 0.5 million US\$ 0.4 million US\$ 0.1 million US\$ 0.3 million US\$ 1.1 million that have contributed significantly to the successful implementation of the scale-up process so far.

The Bahamas $\mathrm{MOH}$ has consistently provided leadership at the national and Caribbean regional level in combating HIV/AIDS. The commitment of the Bahamas $\mathrm{MOH}$ at the highest level to the scaleup initiative was key to the success of the initiative. The $\mathrm{MOH}$ led the development of the process, ensuring consultation with all levels of the health sector as well as with partners from other key sectors. Through its actions the $\mathrm{MOH}$ created a solid foundation that permitted collaboration, planning, and program execution. A number of groups organized themselves into a coherent support network working in collaboration with and under the leadership of the Bahamas $\mathrm{MOH}$ to provide support services to PLWHA at various levels. These groups included the AIDS Foundation of the Bahamas, the National Insurance Board, the Department of Social Services of the Ministry of Social Services and Community Development, private insurance companies, unions, and other groups from civil society.

It is national policy in the Bahamas that all training of laboratory staff and organizational development. Of the funds committed, US\$ 500000 had been disbursed as of November 2004. The Clinton Foundation in late 2002 also committed to financially support the scale-up process, and by December 2003 had disbursed US\$ 1 million to fund specific elements of the program of work. However, it is important to note that scaling up in the Bahamas did not depend on receipt of external funds, but actually began in late 2002, financed completely by the Government of the Bahamas. As of September 2003 the Bahamas MOH had used additional resources assigned by the Government to the National AIDS Program and health services to increase the numbers of patients receiving ARV therapy by almost 1000 at two specialized clinics, on the islands of New Providence and Grand Bahama.

\section{CONDITIONS FAVORABLE TO SCALING UP IN THE BAHAMAS}

An evaluation of the Bahamas experience makes it possible to identify a number of conditions residents should have universal access to essential health services and social services. The Bahamas supports an extensive and well-planned health infrastructure that provides preventive and primary health care services through a system of public hospitals and community clinics. Approximately $85 \%$ of the population receives care through the public health system (in general, high-income individuals use the private sector). Individuals are asked to contribute to the cost of care in the public system, but services are not denied due to an inability to pay.

Since the first days of ARV use in the Bahamas, the National AIDS Program has promoted the use of the most cost-effective ARVs in the prevention of HIV transmission from mother to child and in triple therapy. The Bahamas has identified appropriate qualified sources of ARV medicines, from both original-branded and generic drug manufacturers (10), and has minimized drug costs in combination therapy through price negotiations brokered by the Clinton Foundation (11), thus increasing the number of patients who can be treated.

\section{LESSONS LEARNED}

The scale-up process has resulted in the Bahamas providing ARV treatment to $100 \%$ of the target group for 2003, and approximately $35 \%$ of the total target group for 2005. A number of important lessons can be drawn from the process in the Bahamas, as described in the following five subsections. 


\section{The importance of political leadership and commitment}

The will and political commitment of the Government of the Bahamas to move forward in scaling up has been critical to the success of the process. Effective leadership is essential to mobilize all stakeholders in the process, including PLWHA, the pharmaceutical sector, labor unions, and health professionals. The time and effort required to develop and coordinate an integrated approach to scale-up is considerable, as evidenced by the experience in the Bahamas. However, the time and effort that national authorities have invested in the process has led to the development of partnerships that effectively draw upon the experience of national and international institutions and experts.

\section{An integrated approach accelerates the process, but it requires effective management}

A multidisciplinary approach to scaling up HIV/AIDS care and treatment accelerates the rate at which PLWHA can access care and treatment. A multidisciplinary approach also develops momentum at the national level and facilitates participation and achievement of results. However, the roles and responsibilities of members of the multidisciplinary team must be clearly delineated by the national authorities during the initial planning phase. The team should be led by an individual with experience in program management, coordination, and execution. That person does not necessarily have to be a clinician.

\section{Managerial, administrative, and technical tools are essential to support scale-up planning and implementation}

Guiding principles, a conceptual framework, and a methodology for planning are essential for the development of the scale-up project (12). The scale-up model and the tools that are required for planning and implementation may differ from country to country, depending on resource availability and capacity (13). Resource and capacity assessment tools are required to evaluate the performance of the health system and the services provided. Such an evaluation permits the identification of gaps within the health system, at the organizational level, or in service provision that may hinder an effective scale-up process. Costing tools are also required to assist national authorities in determining accurate estimates of costs and future funding requirements.

\section{Identifying cost savings in the provision of existing services may partially fund the scale-up process}

The identification of cost savings in the provision of existing care and treatment services may be critical in identifying funds for scale-up. In the case of the Bahamas, ARV costs were reduced from approximately US $\$ 3000$ to US $\$ 480$ per patient per year, facilitating a rapid expansion of treatment coverage.

\section{Sustainability depends on mobilizing and scheduling resources}

Clear consideration must be given to additional financing sources for scale-up once costs have been determined. In the case of the Bahamas there is a financing gap of approximately US\$ 22.4 million for a three-year period that must now be addressed. Developing a human resource plan for the scale-up is also critical to the success of the operation. Due consideration must be given to human resource requirements in relation to the schedule for scale-up, as well as to the policy for recruitment and the time required to contract and train health professionals. Addressing human resource issues should be initiated at the earliest possible stage as the development of human resource capacity is considered the rate-determining step in scaling up.

\section{CONCLUSIONS}

The process developed by the Bahamas $\mathrm{MOH}$ in scaling up HIV/AIDS care and treatment has produced noteworthy results, as shown by the rapid increase in the number of PLWHA accessing ARV treatment. Through political commitment and strong leadership, the Bahamas $\mathrm{MOH}$ achieved the establishment of a multidisciplinary team that combined national expertise and local knowledge with international expertise and support. The partnership was not limited to the health sector, but encompassed the labor and private sectors, social services, and the community.

The success of the approach developed in the Bahamas can be characterized in a few succinct phrases. Effective communication facilitated the dissemination of information and the involvement of all partners. Sound planning allowed a phased increase in health service delivery. Good management practices maximized the value of the input from the various partners. Solid leadership made it possible to set clear objectives and targets, coordinate efforts, and increase the partners' motivation. 
In addition, there have been indirect benefits from the approach, such as with the process leading to a review of the health system in the Bahamas.

In the future the Bahamas will face two major challenges to ensuring sustainability in HIV / AIDS care and treatment. Additional human resources will have to be recruited and trained, and financing will have to be secured to continue the scale-up process. Such challenges often appear insurmountable, given the resource limitations that small nations face. However, a clear rationale now exists to address these issues, as life expectancy and quality of life for a large number of PLWHA in the Bahamas have already been improved through the expansion of HIV / AIDS care and treatment services. cado un rápido aumento del número de personas con infección por VIH o sida que tienen acceso al tratamiento con antirretrovíricos y a la atención de salud. Este proceso de rápida ampliación se ha visto facilitado por el establecimiento de un equipo multidisciplinario con gran experiencia en ciertas áreas clave, por la creación de una metodología para identificar carencias en los servicios de salud, y por la adopción de un plan que aprovecha los recursos existentes y los logros obtenidos en el pasado. Sigue habiendo la necesidad de preparar recursos humanos con la capacidad para responder a las exigencias del proceso de ampliación, así como de identificar nuevas fuentes de financiamiento para garantizar su sustentabilidad.

Palabras clave: síndrome de inmunodeficiencia adquirida, infecciones por VIH, agentes antirretrovirales, programas nacionales de salud, prestación de atención de salud, Bahamas.

\section{SINOPSIS}

\section{Enfoque multidisciplinario para ampliar el tratamiento y la atención de pacientes con infección por VIH y sida: la experiencia de las Bahamas}

Las Bahamas han estado poniendo en práctica un proceso de ampliación intensivo, práctico e integrado que ha provo-

\section{REFERENCES}

1. Organización Panamericana de la Salud. Situación de salud en las Américas, indicadores básicos. Washington, D.C.; 2003. (OPS/AIS/03.01)

2. Joint United Nations Programme on HIV/AIDS and the World Health Organization. Bahamas. Epidemiological fact sheet-2004 update [Web page]. Available from: http://hivinsite.ucsf.edu/pdf/ UNAIDS/Bahamas_en.pdf Accessed 2 November 2004.

3. Treco RNM. The Haitian Diaspora in the Bahamas [Web page]. Available from: http://lacc.fiu.edu/research publications/working_papers / working_paper_04.pdf Accessed 2 November 2004.

4. Caribbean Epidemiology Centre. The Caribbean HIV/AIDS epidemic. Epidemiological status-success stories. A summary. CAREC Surveill Rep. 2003: 23(Suppl 1);1-18.

5. Pérez-Casas C. HIV/AIDS medicines pricing report update December 2000. Setting objectives: is there a political will? [Web page]. Available from: http:/ / www.accessmed-msf.org/ upload/ReportsandPublications/49200
113585/Durban\%20report\%20update\% 20dec\%202000.pdf Accessed 2 November 2004.

6. Pan American Health Organization. Antiretroviral prices agreed in the $\mathrm{Ca}$ ribbean negotiation (July 2002) [Web page]. Available from: http://www. paho.org/English / AD / FCH / AI / negociaciones-arv-car-18.doc Accessed 4 November 2004.

7. Fitzgerald J, Gomez B. An open competition model for regional price negotiations yields lowest ARV prices in the Americas. In: Medimond. International proceedings of the 8th World STI/AIDS Congress. Bologna: Medimond; 2003. Pp. 7-13.

8. Pan American Health Organization. Framework for the Accelerating Access Initiative in the Caribbean, Bahamas, July 2002 [Web page]. Available from: http://www.paho.org/common/Display. asp?Lang=E\&RecID=5849 Accessed 25 May 2004

9. Pan American Health Organization. Understanding and responding to HIV/ AIDS-related stigma and discrimination in the health sector. Washington, D.C.: PAHO; 2003.
10. World Health Organization, Procurement, Quality and Sourcing Project. Access to HIV/AIDS drugs and diagnostics of acceptable quality. Suppliers whose HIV-related products have been found acceptable, in principle, for procurement by UN agencies [Web page]. Available from: http://mednet3.who. $\mathrm{int} / \mathrm{prequal} / \mathrm{hiv} / \mathrm{hiv}$-suppliers.doc Accessed 24 May 2004.

11. AIDS.ORG. Clinton team lowers drug price 7-fold in Caribbean [Web page]. Available from: http://www.aids.org/ atn/a-389-04.html Accessed 4 November 2004 .

12. World Health Organization. A public health approach for scaling up antiretroviral treatment: a toolkit for programme managers. Geneva: WHO: 2003.

13. Latin America and Caribbean Regional Health Sector Reform Initiative. Scaling up health systems to respond to the challenge of HIV/AIDS in Latin America and the Caribbean. Washington, D.C.: Latin America and Caribbean Regional Health Sector Reform Initiative; 2003. 